\title{
An autonomous model of health care: Are third parties really needed?
}

\author{
Elmar H. Frangenberg
}

CP Rochester, Rochester, USA; cfran@frontiernet.net

Received 15 July 2013; revised 15 August 2013; accepted 2 September 2013

Copyright (C 2013 Elmar H. Frangenberg. This is an open access article distributed under the Creative Commons Attribution License, which permits unrestricted use, distribution, and reproduction in any medium, provided the original work is properly cited.

\section{ABSTRACT}

This proposal offers a novel approach to the organization and financing of health care and is explored for its impact on the current United States system as the most prominent outlier regarding excessive cost in relation to value. The unique nature of health as a private and common good as well as a foundation for equal opportunity has eluded satisfactory management through either market forces or government intervention. The remedy is an independent, citizen-carried cooperative administrative structure, whose members own and apply their aggregate assets for their own benefit according to democratic principles. Citizens are assessed at a collectively approved rate of equitable tax deductions proportionate to their means for a designated health care fund. The resulting single payer guarantees standardization of services and reimbursements with an expanding emphasis on outcome towards optimum population health. Transparency ensures parity and flexibility for diversity and a goal of personalized medicine. All persons are enrolled on the basis of their civil status as beneficiaries. A close partnership between integrated providers and patients is practiced towards an affordable balance between investment in and value of services. Thus financing is a closed loop and therefore the most effective cost control mechanism at the individual and collective levels. Other than a regulatory and oversight function of government, the traditional third parties, namely employers, insurers and public subsidizing entities, are no longer required for catering to individual health care needs. Useful functions of existing institutions are transitioned into direct collective consumer control. Far reaching positive social, economic and political consequences are explored. The principles of this new approach have general societal appeal.

Keywords: Consumer Owned Plans; Fixed Global Budget; Integrated Provider Organization; Internal Cost Control; Universal Societal Applicability

\section{INTRODUCTION}

Overall health spending in member countries of the Organization for Economic Co-operation and Development (OECD) followed a long-term trend of rapid increases of nearly five percent over the period of 20002009, until cuts in outlays imposed by a global recession reversed this direction [1]. A similar trend was seen in the United States (US) health economy [2]. Health care spending grew by 3.9 percent to an annual expenditure of $\$ 2.6$ trillion or $\$ 8402$ for each individual in 2010, equal to 17.9 percent of GDP [3]. The total expenditure for individual health care is approximately double the amount of other industrialized nations and has wiped out any real income gains over a decade for an average US family [4]. Yet there is scarce evidence that Americans get better value for their dollar [5]. A few examples illustrate this point. Diabetes prevalence is twice as high as 12.5 percent compared with England at 6.1 percent. In the same study, hypertension is about ten percentage points more common and all heart diseases six percentage points higher in the US [6]. Between 1997-98 and 2002-03, the US showed the highest, relative, avoidable death rate in comparison to fourteen other industrialized countries [7]. A recent comparison of the health care systems of seven industrialized countries ranked the US last for criteria of access, patient safety, coordination, efficiency and equity [8]. The most disturbing deficiency is the lack of universal access. The US system is the most expensive in the world, yet has left 49.9 million people uninsured [9]. One possible solution is demon- 
strated in a comparison between the US and Canada, where the universal model of health care has been shown to reduce most disparities in access to care [10]. In reverse, the adoption of private health insurance is predicted to have distinct negative effects of creating inequity in access for low-income groups in Canada [11]. An alternative solution is offered from an historical perspective.

Continually growing supply generates its own demand and results in the phenomenon of "inherent scarcity" in health care [12]. This fundamental observation has been the basic challenge for all socially oriented health care systems which have been introduced and discussed during modern industrialized times for 120 years, if one gives credit to the Bismarck model of 1883 in Germany as the first national health care system [13]. Premiums were contributed jointly by workers and their employers. The Beveridge scheme was the basis for Britain's National Health Service, which considers health care a public benefit and is paid by the government as owner and provider. The National Health Insurance model with features of each of the above is realized in Canada, Australia, South Korea and Taiwan. Finally the out-of-pocket model is practiced in most underdeveloped and poor countries. The well-to-do can avail themselves of health care; the others depend on charity. The US health care system as the most prominent outlier with excessive cost, unequal access and fragmented elements of all four models presents itself as an ideal target for an innovative approach.

Regardless of vantage point, be it a quest for universal health care or a market driven system, it is every working citizen in the role of income producer and taxpayer, who directly or indirectly shoulders the vast national health care bill. In a different approach, an expanded dimension of autonomy may lead towards a citizen carried fair health care system [14]. The traditional triangular administrative framework consists of the health care consumer, the provider and a third entity, variably insurer, government or employer or all of these, which are intermediary between the physician and patient. Eliminating the third entity will leave the prospective patients and their providers as the only stakeholders in a novel health care model to solve the problems of access and cost.

\section{THE NEW DECISION MAKERS}

This proposal elevates health care consumers to an exclusive role in the contribution to and the allocation of all health care resources. Civil status as citizen and payment of a health care tax according to means are the only requirements for being “insured”. Goodman and Musgrave [15] advocated for empowering patients and responded to the claim that "Individuals are not smart or knowledgeable enough to make wise decisions" with the pointed question: "If that argument is persuasive in health care, why isn't it equally persuasive in every other walk of life?" Americans look back on a more than 200 year history of government by the people for the people. They are well positioned to apply this tradition to health care as a pervasive and existential concern.

\subsection{Organization}

In this vision, all members of society are bonded together in a nationwide cooperative of self insured, actual or prospective health care consumers. This administrative entity is defined as an autonomous institution which is jointly owned, governed and financially sustained by its members, who use its facilities and services. This feature of self-government entails a new civic duty for all competent enrollees, namely voting on issues concerning health care in addition to the political arena, specifically electing representatives to a governing board according to democratic principles. Each member has potentially two roles, one universally applicable as beneficiary and the other, depending on income and means, as contributor. Each citizen enrollee is means tested and assessed for a uniform pretax deduction.

Wide differences in socioeconomic conditions are expected in any statistical sample of prospective health care consumers, including a minority of wealthy individuals as well as a majority of average earners, minors and a small proportion of disabled and financially dependent persons. Any member of society may on account of personal misfortune, the lottery of life or prolonged illness become dependent. After recovery or reentry into the workforce this same individual will again be subject to means testing for the size of the newly owed contribution. An infant will grow from a state of dependency to a mature adult with earning power to assume the most common dual roles of beneficiary and contributor. These encompass mostly those who currently receive their health care benefits through their employment contracts in the private or public arena. All citizens in any socioeconomic situation or any level of competency are at some point in their lives presumed to be in need of health care and are without any reservation treated as fully privileged participants in the health care cooperative. In practice, high level executives and assembly line workers are assessed on their individual incomes for their health care tax as contributors and beneficiaries, whereas associated companies or businesses are no longer relevant for their benefits.

\subsection{Financing}

Traditional funding sources for health care are under increasing pressure. Employers anticipate greater cost 
sharing with their workers parallel to an expected increase in expenses for benefits [16]. Employers face the "play or pay" provision of the Patient Protection Affordable Care Act (ACA) of 2010 and an unpredictable number may opt out of their traditional obligation altogether. The crushing cost of health care and the lack of adequate protection have led to a uniquely American experience of medical bankruptcy [17]. The McKinsey Center for US Health System Reform [18] observes an accelerated shift from private to public spending and finds that the Medicare program for the elderly and disabled remains the fastest growing payer category at an annual average of 7.6 percent, followed by Medicaid, the combined State and Federal assistance for the poor, at a yearly 6.8 percent, while spending by private sources grew at less than half these rates. Critical reviews of US outlays on health care point to unnecessary spending: A comparison to Canada quoted 31 percent or approximately $\$ 600$ billion in this category, including profits [19]. Other estimates are even higher [20,21].

The potential financial power of the newly designated contributors, now joined in a nationwide cooperative, is demonstrated by a reported gross adjusted income of \$8.4 trillion from 140 million individual returns for the year 2011 [22]. If for example a ten or fifteen percent deduction were withheld from every earner, a total of $\$ 840$ billion, respectively $\$ 1.2$ trillion, would be available for a general cooperative health care fund. This sum closely approaches the above cited total 2010 outlay minus the estimates for unnecessary spending. It is noteworthy that the German system collects 13.5 percent on incomes for part of the health care expenditures [23].

This aggregate nationwide funding institution will naturally reflect the socioeconomic diversity of the population as a whole for the sake of an even and proportionate distribution of the financial burden. This provision will also guarantee elimination of richer or poorer pockets of health care financing. By their collective decision the new enrollees determine how much of a percentage of their pretax incomes will be spent on health care and the resultant amount is capped at that level for a sufficient length of time to allow stabilization and monitoring. The described health care tax falls under the purview of government like any other obligations for the general welfare, for example defense, public education or infrastructure. This annual pretax deduction is to cover all individual health care costs within the collectively approved range of benefits without any need for further surcharges.

The recession of 2007 to 2009 revealed the sensitive relationship between an economic downturn and increasing numbers of uninsured adults [24]. The recently confirmed ACA addresses access through a universal mandate with a justifiable postulate of increased personal responsibility for health, beginning in 2014. About 30 million people will still be left without insurance by 2022 [25]. Reviewers cannot agree in their predictions regarding actual cost savings [26,27]. All attempts at reform, including the evolving implementation of the new health care law have overlooked the potential multifaceted advantage of a pivotal role of the health care consumer. If the burden of financing and the scope of benefits are inextricably interlocked under the direct authority of the contributors and beneficiaries, a needs and means responsive system is possible.

\section{THE CHALLENGE FOR PROVIDERS}

Health care is delivered by the providers, who in a modern society are highly sophisticated and complex systems of physician groups, nurses, hospitals and other health care facilities and diverse ancillary personnel. Favored by the current health care system medical practitioners and allied professionals have priced their services out of the range of affordability. In a realistic judgment "the title based supremacy of doctors within the occupation's domain is not supported by what they are offering society at large" [28]. McMahon and Chopra [29] pointed out that "certain specialties have increased their spending at the expense of others, contributing in part to the current sustainable growth rate impasse in Medicare", and see a possible solution in the creation of a value-based payment system. Physician specialty groups have responded in a timely manner by appealing to their colleagues in a nationwide effort to reconsider indications for a list of interventions, which have been proven to be either unnecessary or even harmful, for example early imaging for most incidents of back pain, cardiac stress tests for patients without coronary symptoms, cancer treatments for terminal disease states, or antibiotics for mild to moderate sinus distress [30]. These insights strengthen the call for comparative effectiveness research [31,32]. Shared funding between consumers and providers is appropriate, since both parties will derive benefits within the specific context of this proposal.

\subsection{Orientation towards Outcome}

The attending physicians collectively will strive to provide health maintenance and treatment where necessary for their clients within the limits of the overall budget as approved by the new decision makers without recourse to any subsidies. It is noteworthy that the ACA is moving in a similar direction by offering financial rewards for most efficient patient management through Accountable Care Organizations, which could consist of multiple provider entities, including physician groups and hospitals and could restore physician autonomy [33]. 
Historic precedents and current models of provider organizations have been critically reviewed for their impact on individual care and a new expectation of increased attention to population based medicine [34].

\subsection{Realigning Medical Specialties and Reimbursement Scheme}

Attending physician groups must be variable enough in their representation of specialties to have the necessary broad spectrum of services available for the multitude of clinical challenges, which are to be expected from a diverse clientele. Physician organizations may find it necessary to realign and guide specialty choices according to need among their professional ranks to be able to respond to the new emphasis on primary care consultations for lifelong prevention planning. Such adjustments are predicted to shift reimbursement schemes from the traditionally lucrative specialty interventions to a generalist practice orientation. The traditional fee for service reimbursements are replaced by fixed budget maintenance contracts between the collective membership of the new cooperative and provider groups on behalf of each participant owner. Integrated delivery systems coupled with the proposed patient owned cooperative could be the cure for fragmentation and waste [35].

\section{DISTRIBUTION OF HEALTH CARE BENEFITS}

It follows that the new decision makers and their physicians ideally cooperate to design a basic health care package for general maintenance, including an immunization and vaccination plan, regular clinical and laboratory screening tests, as well as evaluation methods for specific applicable risk profiles. Nearly two thirds of health care costs are concentrated in ten percent of patients, while a relatively healthy fifty percent of the population uses just three percent of the health care dollars [36]. The extent of individual health care consumption varies widely between individuals. On one extreme there is the person who remains fit and agile until death at an advanced age, whereas an infant with a congenital ailment may accumulate millions of dollars in health care expenses in specialized units with or without a favorable outcome. The widespread current effort to introduce universal electronic medical records and Smart Card Technology is timely for the purpose of greatly enhancing a concept of an autonomous standing of each enrollee and will as an added bonus result in significant cost savings by avoiding duplication, enabling coordination of care as well as safety for patients and protection of personal health care information [37]. The development of increasingly accurate genetic profiles may become the basis for individualized, gender, age and risk specific plans of health care for each participant. Profiles of propensities for certain diseases, while excluding others, supports abandoning a soon antiquated concept of primary insured and family dependents.

An individualized action plan based on a personalized risk profile as a basic benefit in a modern health care package will be a specific challenge for the primary care provider without any interference of third parties. This provision is consistent with a modern trend towards personalized medicine [38,39]. Topol [40] predicts that vast digital individual data collection capacity will empower the health care consumer of the future to become a truly equal partner of the treating physician in negotiating an optimal prevention and maintenance plan. Access to information on health was promoted by announcing the MedlinePlus Connect program through the National Library of Medicine [41] and will transform the modern patient into an educated and critical consumer. Individual health is redefined as a private good, which in its many variants ultimately coalesces into a measurable good, the general state of health of a nation.

\subsection{Role of Charity}

The implied idea in any insurance risk pool is the availability of protection, in this context, funds for health care in case of need with the possibility that contributions may never be spent for the sole benefit of the contributor. Progressive taxation has been justified in a modern society by the understanding that the more any person gains from living and working in a favorable socioeconomic environment, the higher and the more compelling is the obligation to contribute to the general welfare and to maintain the status quo. Applied to health care in particular potentially large pretax deductions may be appreciated by society of what lastly, dependent on personal moral values, may be interpreted as a voluntary, or negatively viewed, an "involuntary charitable" gift by citizens with sizable means on behalf of the whole. The concept of helping those who are less fortunate is advocated by all major religions. Specifically in the area of health care Schlesinger [42] has pointed to the "importance of need as a rationale for collective intervention in medical care”. There is no assurance that the outlay for individual health care will ever be fully recovered either by the patient or by organized contributors.

\subsection{Right to Property and Its Redistribution}

The past history has revealed that a promise to provide every health care benefit to every member of even the wealthiest societies at any time in the future is highly utopian and presumptuous. Daniels [43] argues that reasonable resource constraints will require judgments about which medical needs are more important to meet 
than others. Therefore "priority setting and rationing is thus a requirement of justice, since meeting health care needs should not and need not be a bottomless pit”. In the proposed democratic decision making process responsibility for any denial of service is distributed over all competent voting members of the cooperative, and thus presumed to be morally supported, especially, since such negative responses affect each member equally in similar clinical situations and is essentially based on a dire lack of means. This process contrasts sharply with the current practice of denial of services, which in the public perception arises from a profit motive and has placed the managed care concept into an unfavorable light [44].

The Oregon Plan has become known as an attempt to practically implement a basic package of health care for Medicaid recipients and distinguishes between category I benefits, for example "birth of a child and maternal care", "preventive care" and "life threatening diseases" and lower ranking lists of nonfatal, self-limiting, or inconsequential conditions and interventions [45]. Engelhardt [46] refers to these efforts as the "best example of an open democratic dialogue creating a basic package of health care". At the same time he warns that secular moral limitations argue against uniformity in health care packages and in favor of the affirmative acceptance of a diversity of approaches to providing health care.

A current controversy over women's health, which is sustained by almost evenly divided ideological and religious opinions on reproductive issues, could be solved by creating two cooperatives. They would still be large enough to reflect the socioeconomic diversity of the nation and either include or exclude controversial interventions, namely contraceptive measures or abortions. Thus contributing members with a conservative orientation are not forced to financially support measures to which their conscience is morally opposed.

At an ideal juncture, when universal access is realized, a free society must allow individual health care consumers with extraordinary means to apply their abundant private resources for their own benefit, after they have fulfilled their basic obligation to the cooperative, which may be substantial. It is conceivable that the results of such health related privately sponsored endeavors may eventually be beneficial for many others. These ethical reflections are consistent with the dictum of an American philosopher: "Social and economic inequalities, for example inequalities of wealth and authority, are just only if they result in compensating benefits for everyone, and in particular for the least advantaged members of society" [47].

\section{COST CONTROL}

The core idea is the creation of a closed loop for the flow of the available funds. The ideal result will be a balanced budget.

\subsection{Individual Level}

The most immediate effect on costs is generated at the day to day scenario of health care demand and delivery at the level of the individual consumer and provider. Each enrollee and decision maker is confronted with the direct connection between the request for delivery of an intervention and its financing entity, which now solely consists of the aggregate individually designated taxes as premiums. Each person has emerged into the open as a most visible and transparent source of financing, potentially every fellow citizen and more specifically the other patient waiting to be seen by the doctor. This awareness is expected to encourage everyone to intensify health promoting efforts. Realizing the value of each intervention and the actual return on each health care dollar spent for each consumer's benefit will be a most potent inherent motivator for cost control, comparable to the mundane every day situation in the world of retail. Absolute financial transparency is a nonnegotiable prerequisite. A pervasive deficiency and untenable inequity in the current system was illustrated by a recent study of comparing prices for appendectomy as one striking example of widely discrepant hospital charges for apparently similar services [48].

Furthermore a causal link between individual health promotion and potential cost savings through early recognition and prevention of disease will be experienced in the personal realm. Each voter and decision maker will see the ripple effect from the demand for high cost services on the need for increasing individual contributions. It is no longer a largely anonymous and remote financial institution, which provides the funds or denies the same, but every fellow member of society is a de facto contributor to one's care.

In current practice, targeting individual risk factors reduces the frequency of common scourges. Most cardiovascular disease, a leading cause of morbidity and death, is preventable [49]. Thorpe [50] states that much of the growth in health care spending is linked to modifiable risk factors. Many firms in their role as major contributors in the current system have invested in wellness centers and bonus programs with the hope that encouraging life style changes may reduce costs on behalf of their workers [51]. Popular writers and health care visionaries advocate for improving health through education and appeal to untapped personal insight and resources [52, 53]. Projections into the future may eventually find the traditional term of patient, which describes a soon to be outmoded central aspect of suffering, no longer fully appropriate, because the new aim is maintenance of 
health as primary goal and avoidance of disability, and only secondarily directed towards curing or effectively managing disease. The new approach engages everyone as holder of the purse.

\subsection{Collective Level}

Large scale cost control arises from a newly created positive dynamic tension between consumers as collective payers and providers as reimbursed caregivers. The essence of this compact is a radical shift from reimbursement for defined and coded interventions, to a method of capitation payments for an objective of optimum health maintenance for each individual patient and collectively for a defined segment of the population. The result is an even balance of financial risk for both parties as a built in cost control mechanism. Providers are motivated to maintain optimum health in their clientele, while staying within a fixed budget; consumers are driven to adhere to their negotiated care plans or face service cuts or tax increases.

\section{ROLE OF GOVERNMENT}

The context of this proposal creates a new version of "government" in the form of a self-regulating cooperative with collective powers over its members and the specific mission to provide health care for them. Then there are the traditional familiar institutions at the Federal, State and local levels.

\subsection{Delineation of Authority}

It is clear that the Federal government has the authority to collect the health care tax and rightfully should ensure integrity in the application of the democratic process for election of representatives to the self-governing nationwide health care board of directors. Federal and State governments traditionally have been responsible for quality assurance, for example licensing of the professions. In contrast, determination of the size of a pretax deduction and its structure for different levels of income must be the prerogative of the competent voting members of the cooperative. An absolutely necessary prerequisite for decision making is extensive and detailed information for the voters on the potential scope of health care services for corresponding ranges of each proposed level of taxation.

\subsection{Governing the Common Pool Resource}

Once a general health care fund is established under the ownership of the contributors without any other outside or additional revenues, the situation is akin to a "common-pool resource". Though originally applied to natural systems, basic definitions are pertinent to the health care arena: “As long as the average rate of withdrawal does not exceed the average rate of replenishment, a renewable resource is sustained over time" [54]. Unless health care cost growth can be reduced, major economic problems, including a federal deficit crisis, are in store [55], invoking the allegory of the "tragedy of the commons", congruent with predictions of impending bankruptcy of entitlement programs. In health care, "withdrawal" is the total reimbursement to providers and "replenishment" accrues from the contributions of the membership, which are adjusted according to need of the participants. The author asks, "how a group of principals who are in an interdependent situation can organize and govern themselves to obtain continuing joint benefits when all face temptations to free-ride, shirk, or otherwise act opportunistically” [56]. This implies a mandate for the self-governing authority to safeguard against abuses and enforce quality control measures.

Ideas for the actual collective administration and operative framework may be drawn from the extensive field observations of the author who described the prerequisites for successful cooperative behaviors in managing common resources of nature to safeguard appropriate benefits for the participants. Examples of interrelated remedies are "clearly defined boundaries" of the common resource pool; enabling members to "modify the operational rules"; authority for participants to "monitor” and apply "graduated sanctions”; “minimal recognition of rights to organize" and to allow for multiple operational layers for nested enterprises as parts of larger systems. An independent and efficient approach to "conflict-resolution mechanisms" must be created to solve disputes, distinct from traditional lengthy and costly legal avenues [57]. The underlying guiding principle is that disputes among peers are heard by peers and any resolutions are only pertinent to peers, and enforce the reality, that all decisions will sooner or later affect the decision makers themselves. Efforts are under way to apply Ostrom's design principles to the health care arena [58].

\section{IMPACT}

An immediate effect will be a significant downward bend in the overall health care spending curve. A spirit of competitiveness, financial risk and the incentive to avoid it, often at the expense of consumers, is decisively shifted from outside payers in the current system to the providers and their patients, who lastly are the only parties who can actually and realistically impact the outcome by different, yet complimentary means.

\subsection{Public Health}

One can expect as a long term effect that the built-in 
cost controlling mechanisms at the level of consumers and beneficiaries will minimize unhealthy life styles and promote consumer attitudes towards health as a most valuable personal asset. The outcome can only be an upgrade in any nation's overall health status at reduced cost and improve the ranking of the US health care system in a future international comparison. One wonders how the new approach will deal with the modern epidemic of obesity, when increasing morbidity is reflected in rising health care consumption [59]. Providers likewise face an intense challenge for promotion of community health beyond individual care.

\subsection{Economic Consequences}

All employer contributions to their employees' health care premiums are terminated. Employers regain their competitive edge in international trade, since they are no longer under any formal obligation to provide for health care for their employees. Workers, who are now less expensive to hire and retain, may no longer be at risk to be replaced by outsourcing.

\subsection{Political Repercussions}

Health care is effectively removed from the prevailing divisive political climate, in which the ACA is evolving. Political and government institutions are no longer targets of health care interest groups, namely physicians or insurers, since citizens have taken the administration and regulation of their health and care under their own autonomous authority. Thus catering to individual health needs and desires are no longer a direct burden on the states and national budgets. This change may be particularly timely in view of an increasingly dangerous world and mounting external and internal threats. Out of necessity, government priorities and resources may have to be decisively shifted to national security, defense and the most urgent present problem of initiating economic recovery and decreasing suffocating national debts.

\subsection{Consumer and Provider Autonomy}

Provider organizations will be dealing directly with a newly emerging and empowered, although so far silent force, the consumer representatives. These in turn may easily find common ground and purpose with physicians and other health care providers, whose strongest motivation has always been a service model towards optimization of their patients' most valuable private good, namely health. The current system has often been accused of undue interference with the time honored patient physician relationship. This approach promises to reinforce the unimpeded direct interaction between patient and provider at the day to day practice level as well as be- tween the collective representatives of each of these sole stakeholders.

\subsection{Collective Self-Determination}

Decision making at the consumer level may include the general direction of research funding after the overall goal of promotion of individual optimum health has been accepted. The question of whether the most important remaining targets are specific diseases, extension of longevity, artificial organ replacements, gene therapy or creation of the perfect baby will be answered by the people for the people [60].

\section{IMPLEMENTATION}

An independent, self-sufficient, citizen carried health care system as the ultimate futuristic goal promises remedies for the basic shortcomings of the current scheme, specifically inequality of access and excessive cost.

\subsection{Societal Attitudes and Dynamics}

In comparison to the individual mandate of the ACA, this proposal omits a complex chain of intermediaries, imposes a clearly defined health care tax on all citizens with means and declares every citizen a participant and "insured". In the arena of health care consumers face a deeply personal and a community aspect. Health and its maintenance is the cherished private good, while individuals as participants in a risk pool extend themselves and their concern into a morally binding, inescapable care scheme for others, which in its aggregate whole is the public good.

Putnam [61] elaborates on the concept of social capital as simultaneously a "private good" and a "public good" and points out that a society "characterized by generalized reciprocity is more efficient than a distrustful society" and "frequent interaction among a diverse set of people tends to produce a norm of generalized reciprocity". In turn "social networks and norms of reciprocity can facilitate cooperation for mutual benefit”. At the same time the author laments a broad decline and collapse of a sense of community in American society since its height in the 1950s and 1960s. One might ask whether any chance of realizing this proposal in a modern society is tied to a general restoration of an eroded cultural and moral infrastructure, or whether successful grassroots efforts with small scale models can generalize and stimulate a rebirth towards enabling an all inclusive and viable, independent citizen carried system. Its building blocks are a pervasive awareness of interdependence, practice of universal reciprocity and trust as the ultimate "insurance" and protection against illness. This aware- 
ness highlights human interrelationships, mutual dependencies and solidarity. Those who lacked social ties, were at increased risk of dying from ischemic heart disease, cancer and all other causes of death [62].

Olson [63] offered a novel interpretation of group dynamics to elucidate a logical basis of organized collective action. In this context optimum and affordable health care is the common interest, which is strictly reserved for group members, and thus serves as the appropriate motivator to join and contribute. The aggregated funds are directly and exclusively applied for the benefit of the members of the cooperative. Therefore the proposed health care deduction can be expected to be palatable for the tax payer, as long as the flow of funds is completely transparent and any suspicion of diversion for other than investment in health is avoided. Health and health care are well defined circumscribed core interests of every citizen and have a profound cumulative impact on the general well being of a nation and the productivity of its citizens. There is no apparent partisan quality to dementia or lung cancer, congestive heart failure or diabetes, which on the contrary should be recognized and respected as examples of effective equalizers of mankind. The broad outpourings of empathy following a cluster of recent human tragedies reveal a deeply anchored, universal sense of community and caring and bode well for a realistic chance of implementing this proposal over time.

The internet may be the potentially most effective force to accelerate formation of human relationships and to benefit people's health [64]. At a future evolutionary stage such interaction is imagined to initiate large scale movements towards universal efforts for an optimal state of wellbeing. As soon as a critical number of participants are enlightened by such insights, a future history of health care will be able to define a tipping point, where it suddenly has become commonplace to pursue healthy lifestyles and avoid health hazards and thereby avoid unnecessary expenses.

\subsection{Conversion of Traditional Institutions}

The single most dominant nationwide institution, the Centers for Medicare and Medicaid Services in the U.S. health system gradually introduces representation by citizens and is converted to an autonomous designated health care trust, funded by a universally applied health care tax outside of the federal budget and independent of employers. The envisioned limited, though vital role of the Federal government will be enforcer, no longer caretaker. It may allow for subdivisions into large cooperatives, gradually modifying existing health care traditional insurance corporations by requesting increasing representation by duly elected directors as legal owners, bene- ficiaries and sole contributors. A reserve fund for equalization of the financial burden between satellite cooperatives and for hardship cases may be necessary. During a transitional phase employer contributions may continue with a defined plan of gradual reduction.

The ACA contains provisions for a Consumer Operated and Oriented Plan program, to foster the creation of consumer governed, private, nonprofit health insurance issuers with a focus on competitiveness through integrated care and accountability [65]. These entities could become viable new entrants in the health care field [66]. Though their emphasis on market competition is misplaced, they may serve as transitional vehicles for consumers and their representatives to eventually assume exclusive contributing and decision making roles beyond the ACA, as this proposal advocates. The ultimate goal is a single payer system from which health maintenance contracts are awarded to large provider groups and their referral hospitals which as integrated delivery systems in turn are responsible for optimum physical and mental well being of a defined segment of the population within their assigned budget limits.

On the negative side the pursuit of increased efficiency and effectiveness towards the ultimate goal will siphon significantly large amounts of fluid capital from health care economics, which may lead to increased unemployment in all ranks, if the conversion from the current to the new system were to take place rapidly. Even less drastic saving measures, addressing traditional areas of waste within the confines of the current system, namely failures of care delivery and coordination, overtreatment, and fraud, may lead to serious disruptions, unless one finds respectful pathways of "transition from business models addicted to doing more, to ones that do only what really helps” [67].

\section{CONCLUSION}

Health care financing has historically been approached with multiple schemes of insurance concepts, market competition and government subsidies. Each mechanism attempted to solve the problem of unaffordable care for limited groups, but energized a relentless cost spiral. Health and its care as our most intimate existential concerns should rightfully be removed from any external interference and returned exclusively to our private and collective responsibility, based on a biologically given solidarity in vulnerability and a resultant need for general reciprocity. This proposal asks from the prospective patient, that is every citizen, and each provider as the only two rightful stakeholders in health care a decisive turn to community orientation beyond the economic implications of a biomedical model. Both consumers and providers, each within their unique area of concern and 
newly assigned scope of authority, are to acknowledge the presence of an entire needy population waiting for inclusion. The potential sociopolitical and economic consequences are nothing less than revolutionary.

\section{REFERENCES}

[1] (2012) Organization for Economic Cooperation and Development.

http://www.oecd.org/health/healthpoliciesanddata/oecdhe althdata2012.htm

[2] McKinsey Center for US Health System Reform (2010) Accounting for the cost of US health care. Pre-reform trends and the impact of the recession. McKinsey \& Company.

[3] Martin, A.B., Lassman, D., Washington, B. and Catlin, A. (2012) Growth in US health spending remained slow in 2010; Health share of gross domestic product was unchanged from 2009. Health Affairs, 31, 208-219. http://dx.doi.org/10.1377/hlthaff.2011.1135

[4] Auerbach, D.I. and Kellermann, A.L. (2011) A decade of health care cost growth has wiped out real income gains for an average US family. Health Affairs, 30, 1630-1636. http://dx.doi.org/10.1377/hlthaff.2011.0585

[5] Anderson, G.F. and Frogner, B.K. (2008) Health spending in OECD countries: Obtaining value per dollar. Health Affairs, 27, 1718-1727. http://dx.doi.org/10.1377/hlthaff.27.6.1718

[6] Banks, J.M., Marmot, M., Oldfield, Z. and Smith, J.P. (2006) Disease and disadvantage in the United States and in England. Journal of the American Medical Association, 295, 2037-2045. http://dx.doi.org/10.1001/jama.295.17.2037

[7] Nolte, E., and McKee, C.M. (2008) Measuring The Health Of Nations: Updating An Earlier Analysis. Health Affairs, 27, 58-71. http://dx.doi.org/10.1377/hlthaff.27.1.58

[8] Davis, K.D., Schoen, C. and Stremikis, K. (2010) Mirror, mirror on the wall: How the performance of the US health care system compares internationally, 2010 update. The Commonwealth Fund, 23, 2010.

http://www.commonwealthfund.org/Publications/Fund-R eports/2010/Jun/Mirror-Mirror-Up

[9] De Navas-Walt, C., Proctor, B.D. and Smith, J.C. (2011) US Census Bureau. Current populations reports, P60-239. Income, poverty and health insurance coverage in the United States: 2010. US Government Printing Office, Washington DC.

http://www.census.gov/prod/2011pubs/p60-239.pdf

[10] Lasser, K.E., Himmelstein, D.U. and Woolhandler, S. (2006) Access to care, health status, and health disparities in the United States and Canada: Results of a cross-national population-based survey. American Journal of Public Health, 96, 1300-1307. http://dx.doi.org/10.2105/AJPH.2004.059402

[11] Sampath, P. and Wilson, D. (2012) A case study and state of science review: Private versus public healthcare financing. Global Journal of Health Science, 4, 118-123.
[12] Denier, Y. (2008) Mind the gap! Three approaches to scarcity in health care. Medicine, Health Care and Philosophy, 11, 73-87. http://dx.doi.org/10.1007/s11019-007-9073-3

[13] Reid, T.R. (2010) The healing of America. Penguin Books, New York.

[14] Frangenberg, E.H. (2011) A good samaritan inspired foundation for a fair health care system. Medicine, Health Care and Philosophy, 14, 73-79. http://dx.doi.org/10.1007/s11019-010-9259-y

[15] Goodman, J.C. and Musgrave, G.L. (1992) Patient power: Solving America's health care crisis. Cato Institute, Washington DC.

[16] Health Care Finance News (2011) Deloitte: Employers expect employees will pay more for health care benefits. http://www.healthcarefinancenews.com/news/deloitte-em ployers-expect-employees-will-

[17] Himmelstein, D.U., Thorne, D., Warren, E. and Woolhandler, S. (2009) Medical bankruptcy in the United States, 2007: Results of a national study. The American Journal of Medicine, 122, 741-746. http://dx.doi.org/10.1016/j.amjmed.2009.04.012

[18] McKinsey Center for U.S. Health System Reform (2011) Accounting for the cost of US health care. Pre-reform trends and the impact of the recession. McKinsey \& Company.

[19] Woolhandler, S., Campbell, T. and Himmelstein, D.U. (2000) Costs of health care administration in the United States and Canada. New England Journal of Medicine, 349, 768-775. http://dx.doi.org/10.1056/NEJMsa022033

[20] Pethokoukis, J. (2009) US health care system wastes $\$ 800$ billion a year.

http://blogs.reuters.com/james-pethokoukis/2009/10/26/st udy-us-healthcare-system-wastes

[21] Institute of Medicine (2012) Best care at lower cost: The path to continuously learning health care in America. http://www.iom.edu/Reports/2012/Best-care-at-Lower-Co st-The-Path-to-Continuously-Learning-HealthCare-in-Am erica

[22] Internal Revenue Service Data Book 2011 (2012) Internal Revenue Service, Publication 55B, Washington DC. http://www.irs.gov/pub/irs-soi/11databk.pdf

[23] Busse, R. and Riesberg, A. (2000) Health care systems in transition, Germany. European Observatory on Health Care Systems, 39-51.

http://www.euro.who.int/document/e68952.pdf

[24] Holahan, J. (2011) The 2007-09 recession and health insurance coverage. Health Affairs, 30, 145-152. http://dx.doi.org/10.1377/hlthaff.2010.1003

[25] Congressional Budget Office (2012) Estimates for the insurance coverage provisions of the affordable care act updated for the recent supreme court decision. http://www.cbo.gov/publication/43472

[26] Cutler, D.M., Davis, K. and Stremikis, K. (2010) The impact of health reform on health system spending. Issue Brief. Commonwealth Fund Pub. 1405, 88, 1-14.

[27] Tanner, M.D. (2011) Bad medicine: A guide to the real costs and consequences of the new health care law. The 
Cato Institute, Washington DC.

[28] Wilson, N.W. (2012) Chaos in western medicine: How issues of social professional status are undermining our health. Global Journal of Health Science, 4, 1-19. http://dx.doi.org/10.5539/gjhs.v4n6p1

[29] McMahon, L.F. and Chopra, V. (2012) Health care cost and value. Journal of the American Medical Association, 307, 671-672. http://dx.doi.org/10.1001/jama.2012.136

[30] American Board of Internal Medicine Foundation (2012) Choosing Wisely. http://choosingwisely.org/

[31] Concato, J. (2012) Is it time for evidence-based medicine? The Journal of the American Medical Association, 307, 1641-1643. http://dx.doi.org/10.1001/jama.2012.482

[32] Golub, R.M. and Fontanarosa, P.B. (2012) Comparative effectiveness research. Journal of the American Medical Association, 307, 1643-1645. http://dx.doi.org/10.1001/jama.2012.490

[33] Emanuel, E.J. and Pearson, S.D. (2012) Physician autonomy and health care reform. Journal of the American Medical Association, 307, 367-368. http://dx.doi.org/10.1001/jama.2012.19

[34] Bodenheimer, T. and Grumbach, K. (2012) Understanding health policy. A clinical approach. 6th Edition, McGraw Hill, New York.

[35] Enthoven, A.C. (2009) Integrated delivery systems: The cure for fragmentation. The American Journal of Managed Care, 15, S284-S290.

[36] Emanuel, E.J. (2012) Why accountable care organizations are not 1990s managed care redux. Journal of the American Medical Association, 307, 2263-2264. http://dx.doi.org/10.1001/jama.2012.4313

[37] Smart Card Alliance HealthCare Council (2011) Getting to meaningful use and beyond: How smart card technology can support meaningful use of electronic health records. www.smartcardalliance.org

[38] Legato, M.J. (2006) The plot thickens. Gender Medicine, 3, 243-245.

[39] Millenson, M.L. (2006) The promise of personalized medicine: A conversation with Michael Svinte. Health Affairs, 25, w54-w60.

http://dx.doi.org/10.1377/hlthaff.25.w54

[40] Topol, E. (2012) The creative destruction of medicine. New York: Basic Books.

[41] US Department of Health and Human Services (2011) News release. National Library of Medicine launches medline plus connect.

http://www.hhs.gov/news/press/2011pres/06/20110620a.h $\underline{\mathrm{tml}}$

[42] Schlesinger, M. (2004) Reprivatizing the public household? Medical care in the context of American public values. Journal of Health Politics, Policy and Law, 29, 969-1004. http://dx.doi.org/10.1215/03616878-29-4-5-969

[43] Daniels, N. (2001) Justice, health, and health care. The American Journal of Bioethics, 1, 2-16. http://dx.doi.org/10.1162/152651601300168834

[44] Mello, M.M. and Brennan, T.A. (2001) The controversy over high-dose chemotherapy with autologous bone marrow transplant for breast cancer. Health Affairs, 20, 101117. http://dx.doi.org/10.1377/hlthaff.20.5.101

[45] Perry, P.A. and Hotze, T. (2011) Oregon's experiment with prioritizing public health care services. Virtual Mentor, 13, 241-247.

[46] Engelhardt, H.T. (1996) The foundations of bioethics. Oxford University Press, New York.

[47] Rawls, J. (1971) A theory of justice, 302. Harvard University Press, Cambridge.

[48] Hsia, R.Y., Kothari, A.H., Srebotnjak, T. and Maselli, J. (2012) Health care as a 'market good'? Appendicitis as a case study. Archives of Internal Medicine, 172, 818-819. http://dx.doi.org/10.1001/archinternmed.2012.1173

[49] Kavey, R.W., Daniels, S.R., Lauer, R.M., Atkins, D.L., Hayman, L.L. and Taubert, K. (2003) American Heart Association guidelines for primary prevention of atherosclerotic cardiovascular disease beginning in childhood. Circulation, 107, 1562-1565.

[50] Thorpe, K.E. (2005) The rise in health care spending and what to do about it. Health Affairs, 24, 1436-1445. http://dx.doi.org/10.1377/hlthaff.24.6.1436

[51] Goetzel, R.Z., Guindon, A.M., Turshen, J.I. and Ozminskowski, R.J. (2001) Health and productivity management: Establishing key performance measures, benchmarks and best practices. Journal of Occupational and Environmental Medicine, 43, 10-17. http://dx.doi.org/10.1097/00043764-200101000-00003

[52] Agus, D. (2010) The end of illness. Simon \& Schuster, New York.

[53] Hadler, N.M. (2011) Rethinking aging. The University of North Carolina Press, Chapel Hill.

[54] Ostrom, E. (1990) Governing the commons. Cambridge University Press, New York.

[55] Fuchs, V.R. and Schaeffer, L.D. (2012) If accountable care organizations are the answer, who should create them? Journal of the American Medical Association, 307, 2261-2262. http://dx.doi.org/10.1001/jama.2012.5564

[56] Ostrom, E. (1990) Governing the commons. Cambridge University Press, New York, 29.

[57] Ostrom, E. (1990) Governing the commons. Cambridge University Press, New York, 90-102.

[58] Indiana University (2012) Rippel foundation awards grant to Ostrom, IU research center, to apply insights to health care.http://newsinfo.iu.edu/web/page/normal/16696.html

[59] Brownell, K.D. and Warner, K.E. (2009) The perils of ignoring history: Big tobacco played dirty and millions died. How similar is big food? The Milbank Quarterly, 87, 259-294.

[60] McGee, G. (2000) The perfect baby. Rowman \& Littlefield Publishers, Lanham.

[61] Putnam, R. (2000) Bowling alone. Simon \& Schuster, New York.

[62] Berkman, L.F. and Glass, T. (2000) Social integration, social networks, social support and health. In: Berkman, L.F. and Kawachi, I., Eds., Social Epidemiology, Oxford University Press, New York, 158-162. 
[63] Olson, M. (1971) The logic of collective action: Public goods and the theory of groups. 2nd Edition, Harvard University Press, Cambridge, 64.

[64] Ziebland, S. and Wyle, S. (2012) Health and illness in a connected world: How might sharing experiences on the Internet affect people's health? The Milbank Quarterly, 90, 219-249.

http://dx.doi.org/10.1111/j.1468-0009.2012.00662.x.

[65] US Department of Health and Human Services (2011) Patient Protection and Affordable Care Act; establishment of consumer operated and oriented plan (CO-OP) program. Federal Register, 76, 77392-77394.
[66] Gardiner, T., Neece, R. and Mendelevitz, M. (2012) Realizing health reform's potential: Innovative strategies to help consumer operated and oriented plans (CO-OPs) compete in new insurance marketplaces. The Commonwealth Fund.

http://www.unboundmedicine.com/medline/ebm/record/2 2582450/full citation

[67] Berwick, D.M. and Hackbarth, A.D. (2012) Eliminating waste in US health care. Journal of the American Medical Association, 307, 1513-1515.

http://dx.doi.org/10.1001/jama.2012.362 